\title{
Erratum zu: Bereit für agile Denk- und Verhaltensmuster der VUKA-Welt
}

\section{Erratum zu: \\ Kapitel 4 in: A. Freyth, Veränderungsbereitschaft stärken, https://doi.org/10.1007/978-3-658-28470-1_4}

Kapitel 4: Für Abb. 4.5 wurde die folgende Bildunterschrift im Buch korrigiert.

Abb. 4.5 Unterschiedliche Herangehensweisen in der Komplexitätsmatrix

Die aktualisierte Version des Kapitels finden Sie unter https://doi.org/10.1007/978-3-658-28470-1_4

(C) Springer Fachmedien Wiesbaden GmbH, ein Teil von Springer Nature 2020 